\title{
REPRODUCTION IN THE FEMALE GREEN ACOUCHI, MYOPROCTA PRATTI POCOCK
}

\author{
DEVRA G. KLEIMAN* \\ Wellcome Institute of Comparative Physiology, Zoological Society of London, \\ Regent's Park, London, $\mathcal{N} . W .1$ \\ (Received 22nd September 1969)
}

\begin{abstract}
Summary. The green acouchi, Myoprocta pratti Pocock, in common with many other South American hystricomorph rodents (= Caviomorpha), possesses a vaginal closure membrane which becomes fully perforate only at oestrus and parturition. Partial perforation occurs at other times but does not prevent its use to define cyclical activity. The oestrous cycle, about 40 days, and gestation length, about 99 days, are long, relative to the size of the animal, but are within the range of those of related species. Sexual maturity is reached between 8 and 12 months of age. One or two offspring are born at any time of year although a slight birth peak is seen during the summer months. There is no difference in the growth rate of males and females, but acouchis weaned before 2 weeks of age are retarded in growth. In captivity, breeding success is greatest when a female is housed with a single adult male.
\end{abstract}

\section{INTRODUCTION}

The green acouchi, Myoprocta pratti, a rare hystricomorph rodent from the tropical forests of South America, has been little studied from the point of view of its reproduction either in the wild or captivity. Morris (1962) has briefly described male courtship behaviour, while Wayre \& Wood (1961) report having carried out several Caesarean sections on gravid acouchis. Weir (1967) observed the oestrous cycle of two females.

The present study was made in conjunction with a detailed analysis of sexual and maternal behaviour in this species (Kleiman, 1969).

\section{ANIMALS AND METHODS}

The animals used were all descendants of acouchis derived originally from Ecuador and brought to the Zoological Society of London on three separate occasions between 1960 and 1962. In 1966, fifteen acouchis were made available and, with one exception, all were thought to have been born in captivity. Three types of breeding unit were established: (1) the pair, (2) the pair with one or more juvenile offspring, and (3) a group of adult females and one or

* Present address: Institute of Animal Behavior, Rutgers University, 101 Warren Street, Newark, New Jersey 07102, U.S.A. 
more adult males. Several females were isolated during pregnancy and lactation.

Accommodation varied; rooms (area, $10 \times 9 \mathrm{ft}$ or $10 \times 12 \mathrm{ft}$ ), large cages $\left(5 \times 7 \mathrm{ft}\right.$ to $7 \times 9 \mathrm{ft}$ and all about $5 \mathrm{ft}$ high), and small cages $\left(2 \frac{1}{2} \times 3 \frac{1}{2} \times 2 \frac{1}{2} \mathrm{ft}\right.$ and $4 \times 2 \frac{1}{2} \times 3 \frac{1}{2} \mathrm{ft}$ ) were employed. Pairs and isolated females were maintained in all types of accommodation, but groups or pairs with adolescent offspring were housed only in large cages or rooms. Wood wool or hay was used for nesting material and large cages and rooms were provided with empty pots, wooden crates, logs and rocks for shelter and variety.

All acouchis were maintained under natural lighting conditions except for the occasional addition of artificial light for an hour at dusk during the winter months. Room temperatures generally ranged from $15^{\circ}$ to $22^{\circ} \mathrm{C}$.

The basic diet consisted of a mixture of fruits and vegetables prepared daily, and a pelleted diet (Diet 86, Dixon and Sons (Ware) Ltd), and water were always available.

The presence of a vaginal closure membrane in the green acouchi, which is fully perforate only at oestrus and parturition, provides a ready means of determining the periodicity of the reproductive cycle. The genitalia were examined daily except during late pregnancy and for a few days post partum. Females were weighed weekly and juveniles on alternate days from birth to 80 days of age and thereafter once weekly. Oestrous cycles and gestation lengths were calculated from the lst day of complete vaginal opening or copulation to the day before the next full vaginal opening or parturition.

Weaning was normally carried out at 1 to 2 months of age, but five young (four litters) were removed from the mother before 2 weeks of age to determine the effects of early weaning on later growth and development.

\section{The oestrous cycle}

\section{RESULTS}

In the laboratory, females were polyoestrous and bred throughout the year but, since many animals often conceived during an oestrus shortly after parturition or one occurring mid-way through lactation, the number of observed oestrous cycles is limited. In parous females, the mean of twenty-two cycles was $40 \pm 2$ days (range 16 to 68 days). The distribution of cycles (in parous and nulliparous females) is shown in Text-fig. 1. Two parous females, however, experienced long periods of anoestrus during the course of this study. The vaginal membrane of AF 8 remained imperforate for 184 days between September 1966 and March 1967. She did not conceive at this oestrus and the vagina remained sealed until June 1967 when she was removed from the series. AF 6, whilst isolated, had two 3-month periods of anoestrus during 1967, one from April to July and the other from September to December. Three nulliparous females also experienced long periods of anoestrus. In one (AF 17), perforation of the vaginal closure membrane did not occur between September 1967 and March 1968 (190 days), although the female was housed with an adult male. The other two females, AF 13 and AF 10, had one anoestrous period of 96 and 97 days between May and August and August and November, respectively. 
Most females permanently housed with males conceived during an oestrus mid-way through lactation which occurred, on average, $25 \pm 4$ days post partum (range 7 to $45 ; \mathrm{N}=11$ ). Oestrus in females housed alone during and after parturition recurred after $54 \pm 3$ days $(N=7)$ and was significantly delayed $(P<0.001)$.

The period of perforation of the vaginal closure membrane at oestrus was divided into three stages depending upon the appearance of the vaginal wall and the size of the orifice. During the first stage, lasting 1 to 2 days after complete rupture of the membrane, the vaginal wall became dry and corrugated in appearance; all observed copulations occurred during this stage. In the second stage of 2 to 3 days' duration, the vaginal wall became smoother and a thick white discharge was seen in the orifice. This discharge, probably associated with metoestrus, persisted for 1 to 2 days and was first seen on the day following observed copulations in eight of nine females and on the 1st to 3rd day of vaginal opening in isolated females. In the third stage, which often took 2 weeks to complete, the vaginal orifice decreased in size as the membrane

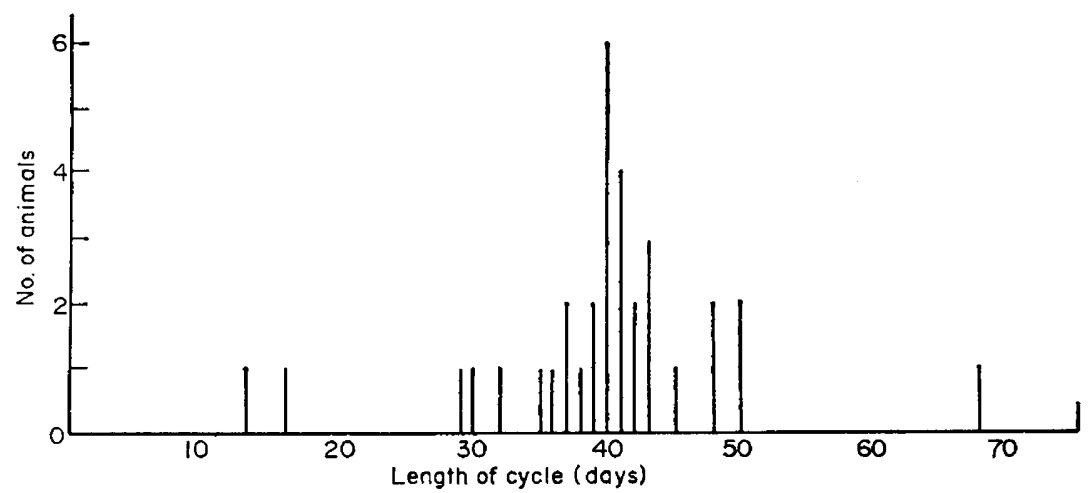

TEXT-FIG. 1. The distribution of oestrous cycle lengths in parous and nulliparous green acouchis.

re-formed while the vaginal wall remained smooth in appearance. In parous and nulliparous females at oestrus and after parturition, the vagina remained open on average for 10 to 11 days (range 3 to $22 ; \mathrm{N}=62$ ).

In some animals, membrane-rupture occurred during pregnancy and between successive periods of oestrus, but the orifice was usually very small and visible for only 3 to 4 days, although it occasionally persisted for as long as 10 days. Perforation took place in a total of seven pregnant females, between 12 to 17 days' gestation (five females) and at 41 (two females), 55 and 85 days' gestation. Similar openings were seen in five animals at different times between two, well-defined periods of oestrus. The vaginal orifice of one adolescent female did not seal completely after first oestrus and partial perforation was seen for most of 9 months during which she experienced two known periods of oestrus, a conception and a normal birth.

Sexual maturity of females

Ten females born during the course of this study experienced at least one oestrus and eight of these conceived before the termination of the investigation. 
Table 1 presents the age and weight of each female at first vaginal opening and conception. No conceptions resulted from these first heats when the females were housed with adult males. Nulliparous females experienced one to two oestrous cycles before the first pregnancy, the average length of eleven cycles

TABle 1

THE AGE AND WEIGHT OF FEMALE GREEN ACOUCHIS AT FIRST VAGINAL OPENING AND FIRST GONCEPTION

\begin{tabular}{|c|c|c|c|c|c|}
\hline \multirow{2}{*}{$\begin{array}{c}\text { Female } \\
A F \\
\text { No. }\end{array}$} & \multicolumn{2}{|c|}{$\begin{array}{c}\text { First } \\
\text { vaginal opening }\end{array}$} & \multicolumn{2}{|c|}{$\begin{array}{c}\text { First } \\
\text { conception }\end{array}$} & \multirow{2}{*}{$\begin{array}{c}\text { No. of heat } \\
\text { before } \\
\text { conception }\end{array}$} \\
\hline & Age (days) & Weight $(g)$ & Age (days) & Weight $(g)$ & \\
\hline $\begin{array}{c}10 \\
11 \\
12 \\
13 \\
15 \\
16 \\
17 \\
18 \\
20 \\
25 \\
\text { Average }\end{array}$ & $\begin{array}{c}83 \\
197 \\
140 \\
129 \\
220 \\
128 \\
153 \\
150 \\
182 \\
87 \\
147 \pm 14\end{array}$ & $\begin{array}{c}466 \\
622 \\
535 \\
628 \\
826 \\
690 \\
691 \\
731 \\
746 \\
600 \\
664 \pm 31\end{array}$ & $\begin{array}{c}289 \\
239 \\
177 \\
225 \\
263 \\
178 \\
388 \\
- \\
232 \\
249 \pm 24\end{array}$ & $\begin{array}{c}818 \\
708 \\
742 \\
782 \\
864 \\
758 \\
938 \\
-\overline{821} \\
804 \pm 26\end{array}$ & $\begin{array}{l}5 \\
3 \\
2 \\
2 * \\
2 \\
2 \\
\frac{3}{2} \\
\frac{2}{-}\end{array}$ \\
\hline
\end{tabular}

* The closure membrane was continuously perforate, but the female seemed to experience only two known periods of oestrus before conception.

being $38 \pm 3$ days (range 13 to 50 days) which was not significantly different from the cycles of parous females. First oestrus did not occur during any special season of the year, but six of eight females first conceived during late winter and early spring, corresponding to births during the summer months. Time of first conception seemed more closely related to body weight than age of animal.

\section{Receptivity}

The onset of oestrus in the female was unpredictable from behavioural observations and receptivity lasted only a few hours. No pair was observed mating more than once, although two females re-mated with strange males 15 and 80 min later. However, three separate males showed no sexual interest in a third female, $1 \frac{1}{2} \mathrm{hr}$ after her first mating. Although animals were observed frequently throughout the day, receptivity was only seen between 09.00 and 12.30 hours, the majority of matings taking place between 10.00 and 11.00 hours. In most cases, receptivity occurred shortly after the rupture of the vaginal membrane but behavioural oestrus and membrane perforation did not necessarily coincide; several females did not mate until 3 to 4 days after the first signs of membrane rupture. Receptive females neither solicited nor repelled males trying to mate, but their behaviour facilitated copulation in two ways. Once mounted, a receptive female would stand immobile and display lordosis but, after 10 to $15 \mathrm{sec}$, she would withdraw from the male, thus inducing further following and mounting. Although females occasionally uttered a threatening sound or the pair might rear up and box one another with the forepaws, copulation was rarely delayed. No vaginal plugs were found, although Weir (1967) has reported their occurrence in this species. 
Pregnancy and gestation period

The average weight gain in fifteen parous and five nulliparous females during pregnancy is shown in Text-fig. 2. The latter gained significantly more $(315 \pm 33.8 \mathrm{~g})$ than the former $(237 \pm 10.6 \mathrm{~g} ; P<0.01)$ but the young females continued to weigh less post partum than multiparous females. Females carrying singletons gained less in weight than those carrying twins $(214 \pm 21$ versus $275 \pm 16 \mathrm{~g} ; P<0.05)$. In all females, the weight gains were greatest during mid-pregnancy.

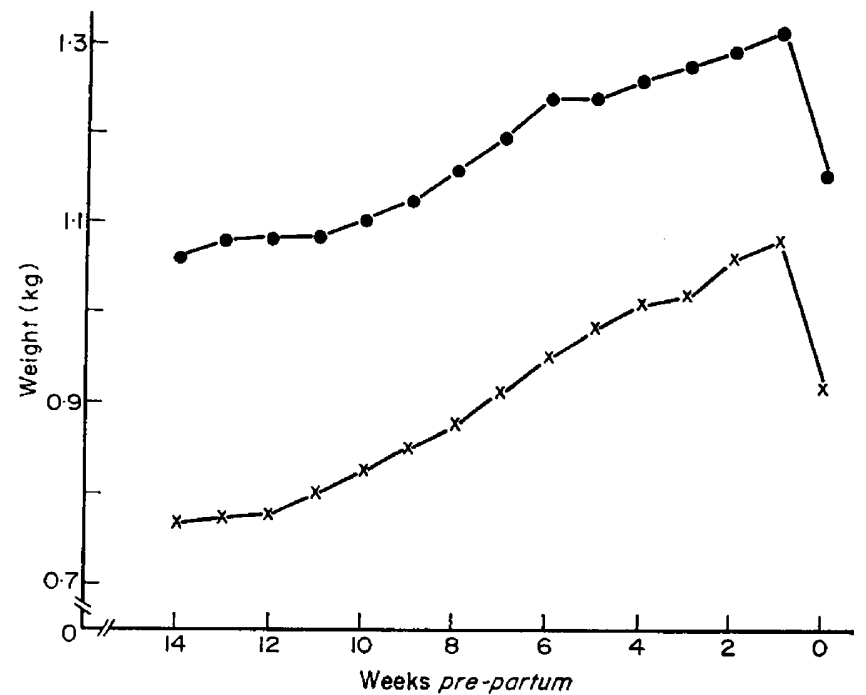

Text-Fig. 2. The gain in weight of parous $(0)$ and nulliparous $(x)$ acouchis during pregnancy.

In all, twenty-one gestation periods were calculated, the average being $99 \pm 1$ days (range 94 to 115 although nineteen of twenty-one gestations were between 94 and 101 days). Five of these were first pregnancies in young acouchis born during the observation period, and the remainder were in parous animals.

\section{Parturition}

The approach of parturition could not be predicted from either behaviour or physical changes, although most females were lethargic during late pregnancy. The separation of the pubic symphysis, commonly beginning about a week before parturition in the domestic guinea-pig (Naaktgeboren \& Vandendriessche, 1962), could not be detected in the acouchi. The closure membrane usually did not rupture until shortly before birth, although, in one stillbirth, vaginal opening and a viscous blood-tinged discharge occurred 2 days before parturition. Of the births observed or timed, most occurred in the morning (one at 06.00 , three at 08.00 to 10.00 and three at 11.00 to 14.00 hours), but one was seen at 18.00 hours. The frequency and total number of contractions before a delivery varied, some females showing few while another had strong ones every 5 to $20 \mathrm{sec}$ for $35 \mathrm{~min}$ before the second delivery. The young was presented head first, and dropped behind the mother as is common in many 
species with foetuses well-developed at birth. Immediately afterwards, the mother removed the membranes and licked the neonate. The membranes were eaten and, in so doing, the mother usually chewed and severed the umbilical cord. In three observed twin births, the interval between delivery of young lasted about $2 \mathrm{hr}$. The length of this interval may have been influenced by the presence of an observer.

Expulsion of placentae was only seen after the last delivery and took between $15 \mathrm{~min}$ and $4 \mathrm{hr}$ to occur; they were always eaten. Several females seemed to retain at least one placenta in the uterus which was slowly expelled as it disintegrated; one female developed a uterine infection from a retained placenta and died.

The young were fully furred, with eyes opened at birth. Within $24 \mathrm{hr}$, most had begun exploring outside the nest area; they were taking solid foods by the middle of the lst week.

\section{Post-natal development}

Between April 1966 and June 1968, thirty-two litters were born comprising eight singletons, twenty-three twins, and one set of triplets. Twenty-eight males and twenty-nine females were born. The average birth weight of twenty-three males $(79 \cdot 3 \pm 2.5 \mathrm{~g})$ did not differ significantly from that of twenty-four females $(74 \cdot 3 \pm 1 \cdot 9 \mathrm{~g})$. Singletons tended to be heavier at birth than twins $(83 \cdot 6 \pm 5 \cdot 6$ versus $75 \cdot 9 \pm 1.7 \mathrm{~g}$ ). No correlation could be found between the birth weights of offspring and either the age or weight of the mother.

Since no differences could be detected in the growth rates of the two sexes, the weights of nine males and fifteen females were combined and can be seen in Text-fig. 3. Most young doubled their birth weight at approximately 17 days of age, and they gained quickly up to 12 weeks. Growth ceased after a year when the parous females had become heavier than the adult males.

Although young acouchis began eating solid foods during the lst week of life, they were usually not weaned by the mother until after 6 to 8 weeks of age. The increase in weight of five animals artificially weaned between 1 and 2 weeks of age and of seventeen animals not separated from the mother until after 40 days of age is shown in Text-fig. 4. Between 13 and 45 days of age, these early-weaned acouchis gained significantly less than the controls $(163 \pm 14$ versus $216 \pm 6 \mathrm{~g} ; P<0.001)$. As adults, four of the five former acouchis seemed to suffer no ill-effects, but the fifth animal, a male, never reached adult weight.

\section{Reproductive performance}

Nine of sixteen observed pregnancies resulted from conceptions during midlactation and four from post-lactation matings when females had access to males during and after parturition. In the other three animals, the interval between the birth of two succeeding litters was 102, 102 and 103 days which strongly suggests that conception occurred in the early post-partum period, although copulation was not observed in any of these animals at that time. Thus, continuous breeding is possible, but not usual.

Although there were conceptions during all months, fewer occurred during the late summer and early autumn which would have corresponded to winter 
births. When females were permanently housed with adult males, $67 \%$ of all conceptions occurred during the 6 months from January to June, thus producing a birth peak from April to September (see Text-fig. 5).

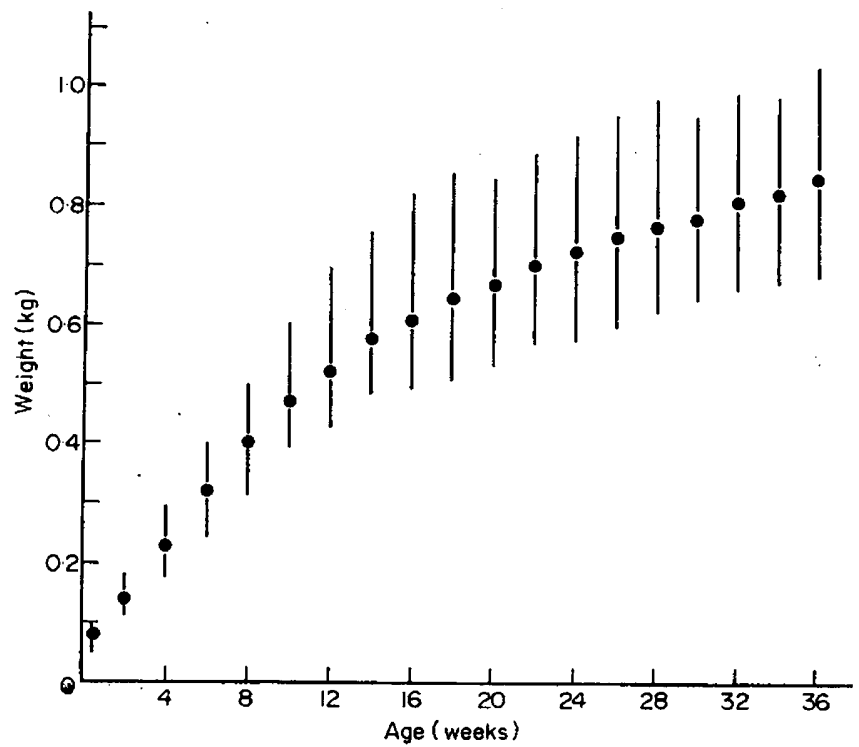

TExT-FIG. 3. The gain in weight of young acouchis. Dots indicate mean weights and vertical lines the ranges of weights.

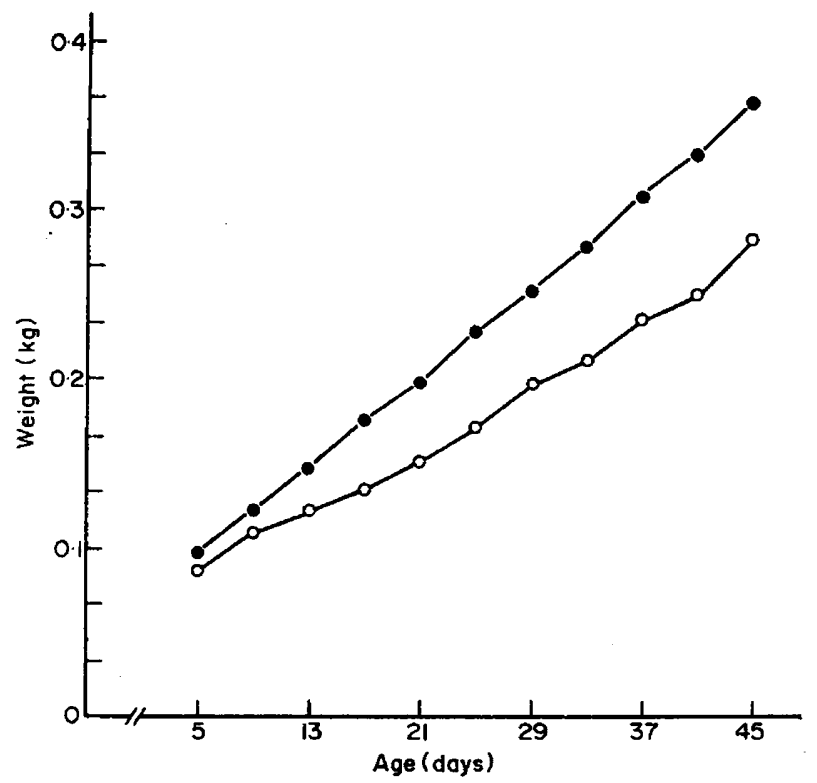

Text-FIG. 4. The gain in weight of early-weaned (O) and late-weaned (O) acouchis between 5 and 45 days of age.

Resorbtion or abortion of foetuses occurred in three pregnant acouchis. Premature termination of pregnancy was assumed because of loss of blood at 66 (AF 10) and 85 (AF 15) days' gestation; no foetuses were found. In AF 10, 
the loss followed a sudden increase in aggression by an adult female cage-mate after parturition. Another animal killed at 60 days' gestation contained one viable and one resorbing foetus.

Of fifty-seven young born during the course of this study, thirty-six survived. A few were stillborn, but the majority of neonatal deaths resulted from maternal neglect. The type of accommodation seemed unimportant but the social environment of the mother did affect maternal care. Isolated females had the least success in rearing their offspring, only seven of thirteen young surviving. These females often ate the young and were the only mothers to do so. Mothers maintained in groups with two or more adult females or with a male and previous litter also showed poor maternal care, only seventeen of twenty-nine young surviving. Typically, these neonates were ignored by the mother. In contrast, females housed with only an adult male exhibited greater maternal

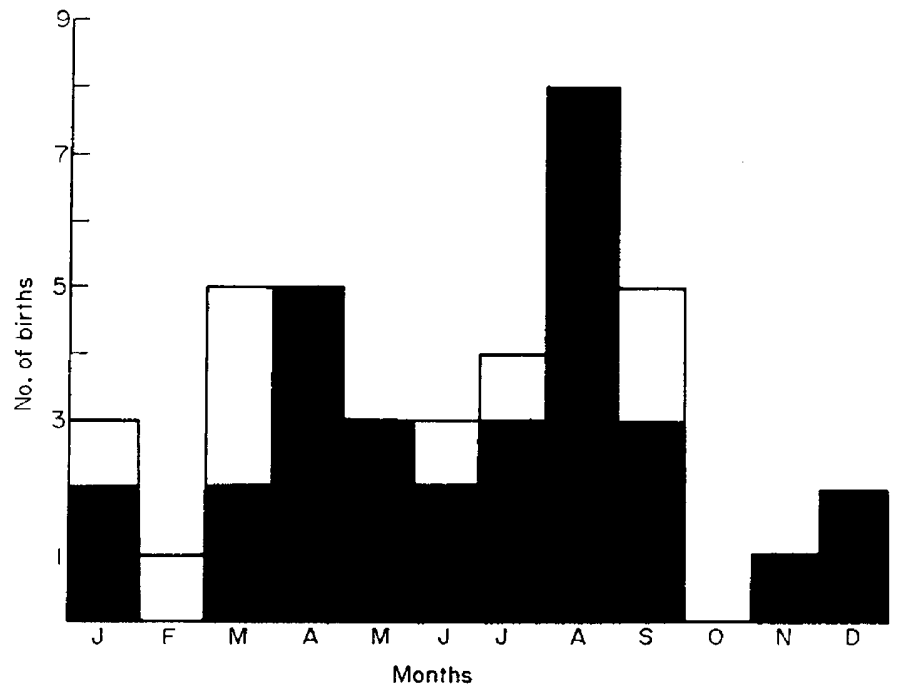

TEXT-FIG. 5. The distribution of births of acouchi females with constant access to males (black area) and with irregular access to males (white area).The projected delivery dates of females killed at a known stage of pregnancy are included.

interest and reared twelve of fifteen young. The survival rate within the three types of social environment was 54,59 and $80 \%$ respectively; overall it was $63 \%$.

\section{DISGUSSION}

The existence of a vaginal closure membrane which is perforate mainly at oestrus and parturition has been observed in all hystricomorph rodents so far studied with the exception of the coypu, Myocastor coypus, in which the membrane ruptures at sexual maturity and does not re-form thereafter (Newson, 1966). In the acouchi, vaginal opening did not indicate unequivocally that a female had had a period of oestrus, since partial perforation occasionally occurred during the oestrous cycle and pregnancy. Ford, Webster \& Young (1951) reported similar events in the domestic guinea-pig, $75 \%$ of females showing membrane rupture at a time other than oestrus or parturition. As in 
the acouchi, these sporadic openings are usually small and resemble the final stage in the closure of the orifice after oestrus.

The oestrous cycle of the acouchi ( 40 days) is long and very variable as was reported by Weir (1967), who found that its average length in two females was 38 and 58 days respectively. Detailed quantitative information is available for only two other species of hystricomorph rodents apart from the domestic guinea-pig, in which the range is 14 to 18 days (Young, Dempsey, Hagquist \& Boling, 1939). The chinchilla cycle has a range of 30 to 50 days, modal length being 41 days (Weir, 1966) and is also reported as averaging 24 days (Asdell, 1965). Oestrous cycle lengths in the coypu vary between 5 and 28 days (Wilson \& Dewees, 1962), 17 and 19 days (Skowron-Cendrzak, 1956), and from less than a week to more than 6 weeks with an average of 2 to 4 weeks (Newson, 1966). Observations on a small sample of agoutis, Dasyprocta aguti, suggest that this close relative of the acouchi has a cycle of 30 to 50 days (Weir, 1967). The recurrence of oestrus in animals kept in captivity (except the guineapig) is extremely variable.

TABLE 2

AGCURATE GESTATION LENGTHS AND LITTER SIZE IN SOME SOUTH AMERICAN HYSTRICOMORPH RODENTS

\begin{tabular}{l|c|c|l}
\hline \multicolumn{1}{c|}{ Species } & $\begin{array}{c}\text { Gestation } \\
\text { (days) }\end{array}$ & $\begin{array}{c}\text { Modal litter } \\
\text { size (range) }\end{array}$ & \multicolumn{1}{|c}{ Reference } \\
\hline Galea musteloides & 49 to 56 & 2 (1 to 5) & Weir (personal communication) \\
Cavia porcellus, domestic & 67 to 71 & $3(1$ to 6$)$ & Goy, Hoar \& Young (1957) \\
Octodon degus & 87 to 91 & $(2$ to 7$)$ & Weir (personal communication) \\
Myoprocta pratti & 94 to 101 & $2(1$ to 3$)$ & Present study \\
Hydrochoerus isthmius & 104 to 111 & 3 & Trapido (1949) \\
Chinchilla laniger & 105 to 118 & $2(1$ to 4$)$ & Weir (1967) \\
Myocastor coypus & 120 to 132 & $(1$ to 9$)$ & Ehrlich (1966) \\
Capromys pilorides & 123 & 2 & Bucher (1937) \\
Lagostomus maximus & 149 to 163 & $2(1$ to 3$)$ & Weir (personal communication) \\
\hline
\end{tabular}

Excepting the cavies, in which pregnancy lasts 50 to 70 days, gestation lengths in hystricomorph rodents that have been closely studied are reported as being over 90 days. Some typical gestation periods as well as litter sizes are presented in Table 2. At present, there is little to suggest that a relationship exists among species between gestation length and litter size. There is also no relation between gestation length and the size of the adult animal; the chinchilla and capybara, Hydrochoerus isthmius, have gestations of similar length although the capybara is seventy-five times heavier than the former.

The existence of an immediate post-partum oestrus and conception is known for several South American hystricomorphs including the guinea-pig (Boling, Blandau, Wilson \& Young, 1939), coypu (Ehrlich, 1966; Newson, 1966), chinchilla (Weir, 1966) and mountain viscacha (Pearson 1949). In the present study, circumstantial evidence (based on the interval between the births of two successive litters) was obtained of the occasional occurrence of a postpartum oestrus in the acouchi; mating, however, was not observed to occur at these times and may frequently be prevented by the extreme post-partum aggression shown by some females (Kleiman, 1969) in contrast with the 
chinchilla, where aggression is said to be reduced during the oestrus immediately after parturition (Weir, 1966).

Despite the advanced development of the acouchi at birth, weaning before 2 weeks of age was found to be detrimental to the rate of growth and one of five animals failed to reach adult weight. Read (1912) noted that early weaning of guinea-pigs was successful if young were initially healthy although the earlier the weaning, the higher the initial weight loss. Although there may be some nutritive factor in acouchi and guinea-pig milk necessary for the growth of young even after they are subsisting primarily on solids, it seems more likely that the advantages to be gained from a long suckling period are social rather than nutritional.

In female acouchis, sexual maturity is reached towards the end of the 1st year of life, weight rather than age appearing to be the chief factor. In the coypu, sexual maturity seems to be dependent on the season of birth, but as the growth rate of young is also related to the date of birth, females born during the winter months grow more slowly and reach sexual maturity later than those born during the summer (Newson, 1966). Ehrlich (1966) reports that sexual maturity in coypu females is dependent partly on social factors, since females kept together experience first oestrus later than females housed with males. A similar social effect was seen in post-partum acouchis who came into oestrus earlier during lactation if they were housed with adult males.

The reproductive performance of the female green acouchi was greatest when individuals were housed with a single adult male. Both isolation and living in a group seemed to have an adverse effect on the course of gestation and the quality of maternal care. In many other species of mammals, the social environment has been shown to affect female reproductive processes, including the onset of oestrus, conception, the course of pregnancy, and maternal care (see Sadleir, 1969).

\section{ACKNOWLEDGMENTS}

I am very grateful to Dr I. W. Rowlands for advice and critical reading of the manuscript. This investigation was supported by the World Health Organization.

\section{REFERENCES}

Asdell, S. A. (1965) Patterns of mammalian reproduction. Constable, London.

Boling, J. L., Blandau, R. J., Wilson, J. G. \& Young, W. G. (1939) Post-parturitional heat responses of newborn and adult guinea pigs. Data on parturition. Proc. Soc. exp. Biol. Med. 42, 128.

Bucher, G. C. (1937) Notes on life-history and habits of Capromys. Mems Soc. cub. Hist. nat. 'Felipe Poey', 11, 93.

EHrLich, S. A. (1966) Ecological aspects of reproduction in nutria, Myocastor coypus Mol. Mammalia, 30, 142.

Ford, D. H., Webster, R. C. \& Young, W. C. (1951) Rupture of the vaginal closure membrane during pregnancy in the guinea pig. Anat. Rec. 109, 707.

Goy, R. W., HOAR, R. M. \& Young, W. G. (1957) Length of gestation in the guinea pig with data on the frequency and time of abortion and stillbirth. Anat. Rec. 128, 747.

KLeiman, D. G. (1969) The reproductive behaviour of the green acouchi, Myoprocta pratti. Ph.D. thesis, University of London.

Morris, D. (1962) The behaviour of the green acouchi (Myoprocta pratti) with special reference to scatter hoarding. Proc. zool. Soc. Lond. 139, 701.

NAaktgeboren, G. \& VANDENDRIEssche, W. (1962) Beiträge zur vergleichenden Geburtskunde I. Z. Säugetierk. 27, 83. 
Newson, R. M. (1966) Reproduction in the feral coypu (Myocastor coypus). Symp. zool. Soc. Lond. 15, 321 .

Pearson, O. P. (1949) Reproduction of a South American rodent, the mountain viscacha. Am. $\mathcal{F}$. Anat. 84, 143.

ReAd, J. M. (1912) Observations on the suckling period in the guinea pig. Univ. Calif. Publs Zool. 9, 341 .

SADLEIR, R. M. F. S. (1969) The ecology of reproduction in wild and domestic mammals. Methuen, London.

Skowron-Cendrzak, A. (1956) Sexual maturation and reproduction in Myocastor coypus. I. The oestrous cycle. Folia biol., Praha, 4, 119.

TRAPIDO, H. (1949) Gestation period, young, and maximum weight of the Isthmian capybara, Hydrochoerus isthmius Goldman. 7. Mammal. 30, 433.

WAYRE, P. \& WoOD, J. G. P. (1961) Some experiences of breeding green acouchis (Myoprocta pratti) in captivity. Int. Zoo Yb. 3, 25.

WErR, B. J. (1966) Aspects of reproduction in chinchilla. 7. Reprod. Fert. 12, 410.

WeIR, B. J. (1967) Aspects of reproduction in some hystricomorph rodents. Ph.D. thesis, University of Cambridge.

Wirson, E. D. \& Dewees, A. A. (1962) Body weights, adrenal weights and oestrous cycles of nutria. F. Mammal. 43, 362.

Young, W. C., Dempsey, E. W., HAgQuist, C. W. \& Bourng, J. L. (1939) Sexual behavior and sexual receptivity in the female guinea pig. F. comp. Psychol. 27, 49. 